\title{
RELAÇÕES ÉTNICO-RACIAIS E GÊNERO NA CIÊNCIA: A SITUAÇÃO DA MULHER NEGRA NO BRASIL
}

\section{Ethno-racial relations and gender in science: the situation of black woman in Brazil}

\author{
Jussara Marques de Medeiros Dias ${ }^{16}$ \\ Nanci Stancki da Luz ${ }^{17}$
}

\section{Resumo}

O objetivo deste artigo é analisar as abordagens sobre gênero e relações étnico raciais na história da ciência e apresentar dados sobre a mulher negra pontuando a forma como a lei 12.711 de 2012 foi instituída na UTFPR, a partir de dados preliminares da engenharia civil (considerada predominantemente de homens) e da Licenciatura de Letras/Inglês (campo predominantemente de mulheres) no campus Curitiba. Também são analisadas as cotas raciais, destacando um recorte de gênero.

Palavras-chave: Gênero, Relação Étnico Racial, Ciência e Tecnologia

\section{Abstract}

The aim of this paper is to analyze the approaches on gender and racial ethnic relations in the history of science and present data on the black woman pointing to how the law 12,711 of 2012 was instituted in UTFPR from preliminary Civil Engineering (considered predominantly men) and Bachelor of Arts / English ( eld predominantly women) on campus Curitiba. Also analyzed are racial quotas, highlighting a clipping gender.

Keywords: Gender, Ethnic racial relationship, Science and Technology

16 Mestranda do Programa de Pós-graduação em Tecnologia da Universidade Tecnológica Federal do Paraná (UTFPR), professora do curso de Serviço Social da UNIBRASIL, Curitiba, Brasil.

17 Doutora em Política Cientí ca e Tecnológica (UNICAMP), professora do Programa de Pós-graduação em Tecnologia e do Departamento Acadêmico de Matemática da Universidade Tecnológica Federal do Paraná 


\section{Introdução}

$\mathrm{Na}$ atualidade, os debates sobre os processos de ações a rmativas, principalmente o concernente as cotas raciais, ensejou grandes discussões no país e ganhou destaca na mídia, particularmente após a aprovação da lei $n^{\circ} 12.711$, de 29 de agosto de 2012. Esta lei dispõe sobre o ingresso nas universidades e institutos federais, determinando que estes deverão reservar $50 \%$ de suas vagas a estudantes que tenham cursado integralmente o ensino médio em escolas públicas. Destas vagas, deverão ser ofertadas ainda $50 \%$ para estudantes com renda per capita inferior a um salário e meio e para estudantes que se autodeterminarem pretos, pardos e índios.

De acordo com dados do Observatório de Gênero ${ }^{18}$, nas três últimas décadas, a desigualdade de gênero brasileira foi reduzida no que se refere ao acesso e permanência das mulheres em todo o processo educacional. Porém, quando consideramos os dados concernentes às mulheres negras, pesquisa realizada pela Articulação de Mulheres Negras Brasileiras $(A M N B)^{19}$ aponta que essas mulheres estão entre os contingentes de maior pobreza e indigência do país.

De acordo com a pesquisa elas têm menor escolaridade e detém uma taxa de analfabetismo três vezes maior que as mulheres brancas e uma menor expectativa de vida. Um número signi cativo de trabalhadoras negras está sem ocupação, sem acesso à previdência, residem em ambientes insalubres e são responsáveis pelo cuidado e sustento do grupo familiar. Dados (IPEA, 2011) explicitam que, no contexto da informalidade $21,4 \%$ das mulheres negras estão no trabalho doméstico e nas menores proporções de trabalho com carteira assinada (23,3\%). Assim, são elas que a partir dos dados sobre renda detém a pior posição na escala social.

Nesta perspectiva, este artigo analisa as abordagens sobre gênero e relações étnico raciais na história da ciência e apresenta dados sobre a mulher negra pontuando a forma como a lei 12.711 de 2012 foi instituída

18 O Observatório surgiu em diálogo com a iniciativa da Comissão Econômica para América Latina e o Caribe - CEPAL - de criação de um Observatório de Gênero para América Latina e Caribe como estratégia de disseminação de informações acerca das desigualdades de gênero e dos direitos das mulheres com vistas a subsidiar o processo de formulação e implementação de políticas de gênero e de políticas públicas com perspectiva de gênero no país. Saiba mais:http://www.observatoriodegenero.gov.br Disponível em http://www.spm.gov.br/acesso-a-informacao/perguntas-frequentes/obig/qual-e-a-importancia-de-um-observatorio-de-genero

19 Disponivel em http://www.globalrights.org/site/DocServer/RELATORIO_CEDAW_FINAL_-_Portugues. pdf $/ 749676568$ ? doc $I D=13324 \&$ ver $I D=1$ 
na UTFPR, a partir de dados preliminares da engenharia civil (considerada predominantemente de homens) e da Licenciatura de Letras/Inglês (campo predominantemente de mulheres) no campus Curitiba. Também são analisadas as cotas raciais, destacando um recorte de gênero.

\section{Mulher Negra: uma construção da Ciência}

Nas pesquisas referentes à mulher, gênero e tecnologia, discute-se a pouca inserção das mulheres nas ciências, destacando-se as engenharias, as áreas exatas e tecnológicas.

Para Silva (1999), é fato incontestável que o meio acadêmico re ete e reproduz estereótipos de gênero especialmente no campo cognitivo. Para a autora, os estudos de gênero e ciências se avolumaram enquadrando-se em três grandes abordagens que são: a estrutural, que analisa a presença, a colocação e a visibilidade das mulheres nas instituições cientí cas; a epistemológica, que questiona os modos de produção do conhecimento a partir de uma crítica aos princípios norteadores do princípio hegemônico cientí co e análise dos discursos e das representações das mulheres nas ciências, com o homem associado a razão e a mulher à natureza.

A mulher negra, porém, historicamente, é vista de acordo com a visão "cientí ca" etnocêntrica europeia, como parte da natureza. Para Stepan (2005) a ciência é uma força produtiva que gera conhecimento e práticas que conformam o mundo em que vivemos. Para a autora, a ciência tem uma grande autoridade moral no mundo moderno, baseada no seu caráter de factualidade, neutralidade e universalidade. Ela produz estereótipos, construções sociais percepções e "técnicas que conformaram interpretações culturais e levaram ao desenvolvimento de estratégias sociais".

Para Citeli (2001), a mulher negra foi construída historicamente pela ciência como um ser inferior como se constata na história de Saartjie Baartmann, da África do Sul, que vai para a Europa em 1810. Sarah Bartmann, como foi batizada depois, media $1,35 \mathrm{~m}$ de altura, era negra, tinha as nádegas grandes e pertencia ao povo de baixa estatura conhecido como hotentote pelos colonizadores. A autora conta como Sarah Bartmann começa a fazer sucesso em espetáculos e logo atrai a atenção de cientistas na França, quando passam a estudá-la. Quando ela morre, com 26 anos, seu corpo é entregue a esses cientistas que dissecam seu cadáver e tiram o molde 
de seus genitais. Cuvier, cientista francês que estuda o corpo de Bartmann, começa a chama-la de Vênus Hottentotte, enfatizando sua sexualidade. $O$ cientista a rma:

Ao tratar do achatamento de seus ossos nasais, Cuvier a $r$ ma que jamais vira "uma cabeça humana mais similar à dos macacos"; discorrendo sobre a anormalidade de seu pequeno crânio (nada surpreendente para uma mulher de 1,35 m), classi ca-a de "estúpida", em virtude da "lei cruel que parece ter condenado a uma eterna inferioridade aquelas raças que têm crânios pequenos e comprimidos". Cuvier teria daí inferido certos comportamentos de Bartmann: movimentos bruscos que recordavam os dos macacos e uma maneira de mexer os lábios idêntica à dos orangotangos. (Citeli, 2001, p.61).

Em relação à sexualidade e as características dos órgãos genitais de Bartmann, Cuvier explicava que "os lábios inferiores dos genitais femininos se desenvolvem muito nas hotentotes e podem chegar a medir de 8 até 10 cm, dando a impressão de uma cortina de pele independente." (CITELI, 201, p. 167). O cientista relacionava sexualidade e animalidade e chegou a a $r$ mar que com a proximidade do Egito, os lábios inferiores do genital deviam diminuir, visto que o povo egípcio era considerado caucasiano.

Schiebinger (2001) a rma que esses valores são formados por circunstâncias históricas e discorda que raça e sexo sejam o mesmo problema no contexto do início do século XIX.

Stepan (2005), ao estudar a eugenia, contrapõe-se a essa visão quando a rma que raça está relacionada ao problema de interpretação cientí ca. Eugenia é considerada uma ciência de "aprimoramento racial" e para a autora, teve uma grande in uência na América Latina.

Para Saf oti (2011) as mulheres negras se constroem como sujeitos políticos a partir do confronto com o racismo patriarcal. A autora (2011) defende que cada linha teórica enfatiza um aspecto do gênero, porém há um tênue consenso: "o gênero é a construção social do feminino e do masculino" mas para ela, há uma estrutura de poder que uni ca as três subestruturas: gênero, classe social, raça/etnia.

Werneck(2009) pontua que as mulheres negras devem ser compreendidas como uma articulação de heterogeneidades, que devem confrontar a dominação eurocêntrica em várias épocas, a modernidade racializada, racista e heterossexista e suas con gurações atuais. 


\section{Gênero, raça e identidade.}

"Se o preto de alma branca pra você é o exemplo da dignidade
Não nos ajuda, só nos faz sofrer, nem resgata nossa identidade".
Jorge Aragão

Essa música de Jorge Aragão resgata um conceito de identidade relacionado a resistência de um povo: "Quem cede a vez não quer vitória, somos herança da memória, temos a cor da noite, Ihos de todo açoite, fato real de nossa história". Castells entende identidade como a fonte de signi cado e experiência de um povo "O processo de construção de signi cado com base em um atributo cultural, ou ainda, um conjunto de atributos culturais inter-relacionados, os quais prevalecem sobre uma fonte de signicado". (CASTELLS, 1999, p.22)

O autor de ne papéis como "aqueles de nidos por normas estruturadas pelas instituições e organizações da sociedade" e identidades "como o que constitui fontes de signi cados para os próprios atores, por eles originadas e construídas por meio de um processo de individuação." (CASTELLS, 1999, p.23). Não se podem misturar esses conceitos, pois o conceito de identidade sempre ocorre em um ambiente marcado por relações de poder. Castells propõe três formas de construção de identidade:

Identidade legitimadora :introduzida pelas instituições dominantes da sociedade no intuito de expandir e racionalizar sua dominação em relação aos atores sociais;

Identidade de resistência: criada pelos atores que se encontram em posições/condições desvalorizadas e/ou estigmatizadas pela lógica da dominação construindo trincheiras de resistência e sobrevivência como base em princípios diferentes dos que permeiam as instituições da sociedade.

Identidade de projeto: quando os atores sociais, utilizando-se de qualquer tipo de material cultural ao seu alcance constroem uma nova identidade capaz de rede nir sua posição na sociedade, ao fazê-lo, buscam a transformação de toda a estrutura social.

A identidade de projeto pode ser exempli cada pelo movimento feminista, que faz frente ao patriarcalismo e à estrutura de produção e reprodução da sexualidade.

Porém, historicamente, a identidade da mulher negra vem vendo construída como inferior, tanto no que se refere ao aspecto corporal (sem beleza), quanto ao intelectual (sem inteligência). 
Utilizando o conceito de Castells, é possível criar política de identidade. A eugenia e o processo de desvalorização do negro, destacando a mulher negra, torna possível pensar hoje em políticas a rmativas que possam propiciar uma minimização não apenas da desigualdade de gênero, mas também das desigualdades étnico-raciais, valorizando a herança que a mulher negra trouxe na sua história. Assim, além da pobreza também deve ser considerado o contexto histórico, onde a classe social, a raça e o gênero estão associados para discutir políticas a rmativas para a população negra.

Werneck (2009) pontua a necessidade de assumir de forma positiva sexo e cor de pele como conceito e identidade da mulher negra. Dessa forma, busca-se desconstruir a identidade legitimadora e "cientí ca" que construiu uma mulher negra a margem das riquezas e conhecimentos socialmente construídos.

\section{A História das Políticas A rmativas na UTFPR}

A Universidade Tecnológica Federal do Paraná é uma instituição Federal que abrange o ensino técnico e o ensino superior. Ela foi transformada de Centro Federal de Educação Tecnológica do Paraná (CEFET-PR), para Universidade Tecnológica em 2005 e hoje, possui 12 câmpus: Curitiba, Apucarana, Campo Mourão, Cornélio Procópio, Dois Vizinhos, Francisco Beltrão, Guarapuava, Londrina, Medianeira, Pato Branco, Ponta Grossa e Toledo.

Em 2007, foi instituído o "Programa de Apoio a Planos de Reestruturação e Expansão das Universidades Federais - REUNI, que de niu como um dos seus objetivos "dotar as universidades federais das condições necessárias para ampliação do acesso e permanência na educação superior".

Este programa pretende consolidar uma política nacional de expansão da educação superior pública, pela qual o Ministério da Educação cumpre o papel atribuído pelo Plano Nacional de Educação (Lei n 10.172/2001) quando estabelece o provimento da oferta de educação superior para, pelo menos, $30 \%$ dos jovens na faixa etária de 18 a 24 anos, até o nal da década.

A partir dessas diretrizes, em 2007, foi aprovado pelo Conselho Universitário da UTFPR para o vestibular e o exame de seleção dos cursos técnicos, o sistema de cotas para alunos que vêm de escola pública (socioeconômicas), aplicadas a $50 \%$ das vagas. O vestibular passa a incluir a nota 
do Exame Nacional do Ensino Médio (Enem) na avaliação e os candidatos passam por duas provas: uma de conhecimentos gerais e outra de conhecimentos especí cos.

Para ter direito às vagas destinadas a cotas públicas, era necessário que os estudantes que zeram o vestibular ou o exame de seleção para o curso técnico comprovem que estudaram todo o Ensino Médio em escolas públicas. No caso dos cursos técnicos, tanto para a modalidade integrada (quatro anos de duração), quanto para a modalidade Proeja - Programa de Educação Pro ssional de Jovens e Adultos (três anos de duração) era preciso também que os candidatos tenham cursado todo o Ensino Fundamental em instituição pública.

Outras mudanças na instituição devem ainda ser destacadas: em 2010, a seleção dos alunos começa a ser feita pelo SISU (Sistema de Seleção Uni cada). progressivamente, os cursos técnicos de ensino médio começam a diminuir, com a mudança do "antigo CEFET" como Universidade Tecnológica", em 2012 gradativamente está sendo discutida e instituída a lei $\mathrm{n}^{\circ}$ 12.711 , de 29 de agosto de 2012 que dispõe sobre o ingresso nas universidades federais e nas instituições de ensino técnico de nível médio. Assim, há uma mudança no edital em relação às cotas, que cam organizadas da seguinte forma:

São destinadas $50 \%$ das vagas ofertadas em cada curso e turno para candidatos que tenham cursado e concluído todas as séries do Ensino Médio regular ou equivalente (técnico, magistério ou Educação de Jovens e Adultos) em escola pública brasileira das esferas federal, estadual ou municipal ou que tenham obtido certi cado de conclusão com base no resultado do Encceja ${ }^{20}$ ou de exames de certi cação de competência ou de avaliação de jovens e adultos realizados pelos sistemas estaduais de ensino. Esses candidatos são denominados Cotistas.

Para se bene ciar de tais vagas, não vale a comprovação de ter o candidato recebido bolsa de estudo em escola privada. As condições étnicas raciais, dessa forma, são associadas a condições de renda e de não acesso a escolas particulares. As vagas de cotistas são divididas em dois grupos:

Grupo 1 - Candidatos oriundos de famílias com renda bruta, comprova-

20 O Exame Nacional para Certi cação de Competências de Jovens e Adultos (Encceja) é uma avaliação voluntária e gratuita ofertada às pessoas que não tiveram a oportunidade de concluir os estudos em idade apropriada para aferir competências, habilidades e saberes adquiridos tanto no processo escolar quanto no extra-escolar. http://encceja.inep.gov.br/ 
da, igual ou inferior a 1,5 salário-mínimo per capita, correspondendo a 50\% (cinquenta por cento) das vagas de cotistas.

Grupo 2 - Candidatos oriundos de família independente de renda (sem necessidade de comprovação), correspondendo ao complemento das vagas de cotistas.

A Proporção de vagas para o conjunto de pretos, pardos e indígenas é a soma do porcentual de pretos, pardos e indígenas do Estado do Paraná, ou seja, de $28,264 \%$ referente ao último Censo Demográ co divulgado pelo Instituto Brasileiro de Geogra a e Estatística - IBGE, aos autodeclarados Pretos, Pardos e Indígenas - atendendo a Portaria Normativa $N^{\circ} 18-\mathrm{MEC}$, de 11 de outubro de 2012, Art. $3^{\circ}$, Inciso II.

Esses grupos são divididos entre o conjunto de autodeclarados pretos, pardos e indígenas e os que não se declararam pretos, pardos e indígenas. Em cada um desses grupos, são divididas as seguintes categorias, de acordo com quadro 1 :

Quadro1: Categorias de cotas da UTFPR, criadas em 2013

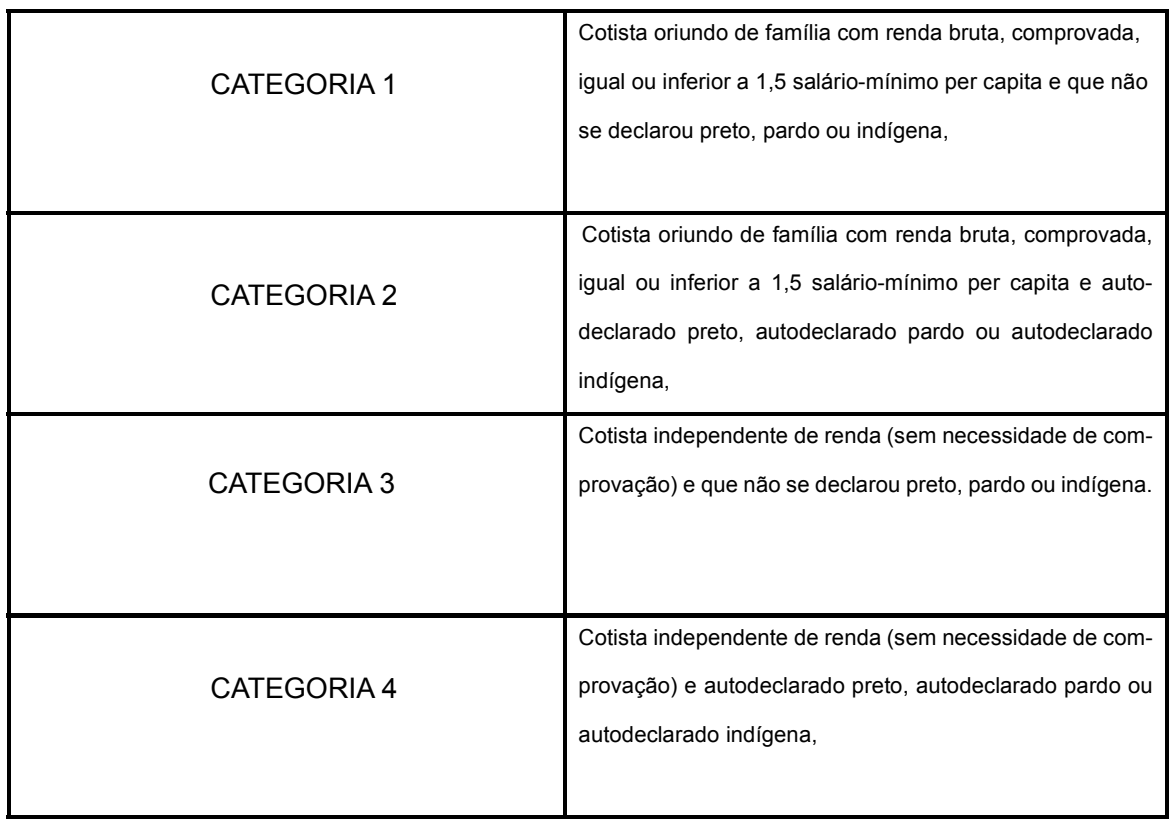

Fonte: Organizado a partir do edital 19/2013 da PROGRAD 
A partir do quadro 1, foi realizada uma análise dos dados referentes aos alunos cotistas dos cursos de Engenharia Civil e Licenciatura Letras/ Inglês, ofertados pela UTFPR, selecionados pelo fato de que, historicamente o primeiro tem um maior número de alunos do sexo masculino e o segundo, tem uma composição discente com maioria de mulheres.

No sistema acadêmico, não há uma especi cação de quem se declarou preto, pardo ou índio, mas a categoria 2 indica que o candidato se declarou preto pardo ou indígena com renda inferior a 1,5 salário mínimo e na categoria 4 e indica que o candidato se declarou preto pardo ou indígena com renda superior a 1,5 salário mínimo, todos advindos de escola pública.

$\mathrm{Na}$ engenharia civil, entre 85 alunos matriculados, 21 são do sexo feminino e 64 do sexo masculino. Em relação às alunas, 9 são não cotistas e 12 são cotistas., com um percentual de 57,14 \% entre as mulheres. Das cotistas, as categorias estão organizadas da seguinte forma:

Categoria 1- 4 alunas

Categoria 2- 3 alunas

Categoria 3- 2 alunas

Categoria 4- 3 alunas

Nesse curso, observa-se que dentre as 6 que ingressaram por meio de cotas étnicos raciais, 3 são com baixa renda.

Em relação ao sexo masculino, há 64 alunos matriculados. Destes, 34 são não cotistas e 31 são cotistas.

Categoria 1- 9 alunos

Categoria 2- 5 alunos

Categoria 3- 11 alunos

Categoria 4- 6 alunos

$\mathrm{Na}$ categoria 2, há 5 alunos, que ingressaram por questões étnico raciais e baixa renda. Dos alunos do sexo masculino, 6 estão enquadrados na categoria 4, referente a pardos, pretos e índios. Isso aponta para uma maior entrada de alunos do sexo masculino com 17,18\% em relação ao todo, do sexo masculino, com critérios étnicos raciais.

Em relação ao curso de Licenciatura em Letras/ Inglês, entre 43 alunos matriculados, 30 são do sexo feminino e 13 do sexo masculino, predominando o maior percentual de alunas. Dentre estas, 15 não são cotistas e 15 são cotistas, distribuídas da seguinte forma: 
Categoria 1- 7 alunas

Categoria 2- 0 alunas

Categoria 3- 6 alunas

Categoria 4- 2 alunas

Destaca-se que, do percentual total de alunas 2 estão enquadradas na categoria 4, referente a pardos, pretos e índios, totalizando $6,6 \%$ de cotistas nesta categoria. No que se refere aos alunos, 9 são não cotistas e 4 cotistas, organizados da seguinte forma:

Categoria 1- 0 alunos

Categoria 2- 1 aluno

Categoria 3- 1 aluno

Categoria 4- 2 alunos

O número de cotistas da categoria 2, referente a pardos, pretos e índios, com baixa renda é menor que o número de cotistas da categoria 4 de negros, pardos e índios, sem critério de renda. Porém, mesmo em minoria relacionada ao sexo masculino neste curso, o percentual de cotistas com critério étnico raciais é maior que o mesmo critério, nas cotas de mulheres.

Assim, a partir desses dados, mesmo com as mulheres constituindo a maioria do corpo discente tanto nos cursos de graduação como de pós-graduação ainda se veri ca uma marcante diferença na distribuição dos sexos por áreas de conhecimento.

Dados do IBGE (2008) referentes ao ano de 2005 apontam que os dez maiores cursos por número de matrícula com os maiores percentuais de matrícula do sexo feminino foram: Pedagogia (91,3\%), Letras (80\%) e Enfermagem $(82,9 \%)$. Já os cursos com os maiores percentuais de matrícula do sexo masculino foram: Engenharia $(79,7 \%)$ e Ciência da Computação $(81,2 \%)$.

Quando se acrescenta a variável raça, veri ca-se na realidade da UTFPR que as mulheres negras também não estão presentes em cursos com presença majoritariamente feminina. As mulheres autodeclaradas pretas e pardas mantém o mesmo baixo percentual nos cursos de Engenharia e Letras. Na Licenciatura de Letras/ Inglês, predominantemente com a presença de mulheres, não há nenhuma cotista na categoria 2 que aponta relação 
étnico racial e baixa renda, apenas duas na categoria 4, mostrando como as mulheres negras não tem acesso a licenciatura. Na Engenharia Civil, há 3 cotistas de baixa renda associada as condições étnico raciais.

\section{Conclusão}

Ao analisarmos o ingresso e permanência na escola, constatamos que o número de mulheres tem superado o de homens. Porém, isto não se verica em todos os cursos, pois em áreas especí cas como nas engenharias, há um percentual maior do sexo masculino.

Ao analisarmos o ingresso e permanência na escola, constatamos que poucas mulheres negras têm acesso à educação superior. De acordo com o retrato das Desigualdades de Gênero e Raça ${ }^{21}$, em 1995 as mulheres brancas tinham um índice de acesso no ensino superior de 9,9\% e as mulheres negras de 2,4\%. Em 2009, essa taxa das mulheres brancas foi para 23,8\% e das mulheres negras para $9,9 \%$, ou seja, um aumento pouco signi cativo comparado às mulheres brancas.

De acordo com Werneck (2009) as disparidades raciais em relação às mulheres negras, potencializadas pela desigualdade de gênero e pelo efeito na escolaridade, tem impacto no mercado de trabalho. A autora destaca que as mulheres negras apresentaram as maiores taxas de desemprego em 2007 , de $12,66 \%$, sendo que no mesmo período a taxa de desemprego de mulheres brancas equivalia a $9,67 \%$, pior que os homens negros $(6,84 \%) \mathrm{e}$ dos homens brancos. (5,61\%).

Não podemos desarticular a discussão da raça e gênero do contexto de pobreza, pois assim podemos contribuir com o enfrentamento do racismo e do sexismo.

21 Disponível em http://www.ipea.gov.br/retrato/indicadores_educacao.html 


\section{Referências}

BRASIL. Ministério da Educação. Lei n 12.711, de 29 de agosto de 2012. Dispõe sobre o ingresso nas universidades federais e nas instituições federais de ensino técnico de nível médio e dá outras providências. Disponível em http://www.planalto.gov.br/ccivil_03/_Ato2011-2014/2012/Lei/L12711. htm. Acesso em 10 abril 2013.

BRASIL. Ministério da Educação. Portaria Normativa $\mathbf{n}^{0}$ 18. Dispõe sobre a implementação das reservas de vagas em instituições federais de ensino de que tratam a Lei $n^{\circ} 12.711$, de 29 de agosto de 2012, e o Decreto $n^{\circ}$ 7.824, de 11 de outubro de 2012. Disponível em http://www.lex.com.br/legis_23866622_PORTARIA_NORMATIVA_N_18_DE_11_DE_OUTUBRO_ DE_2012.aspx Acesso em 10 de abril de 2013.

CASTELLS, Manuel. O poder da identidade (A era da informação, economia, sociedade e cultura, v. 2). São Paulo: Paz e Terra, 1999.

UTFPR. De Escola de Aprendizes a Universidade Tecnológica. Disponível em http://www.utfpr.edu.br/a-instituicao/historico. Acesso em 13 de abril de 2013.

CITELI, Maria Teresa. As Desmedidas da Vênus Negra: gênero e raça na história da ciência. Novos Estudos CEBRAP, n. 61, p. 163-175, 2001.

Wernwck, Jurema. Mulheres negras brasileiras e os resultados de Durban. In: HERINGER, Rosana; PAULA, Marilene. Caminhos Convergentes: Estado e sociedade na superação das desigualdades raciais no Brasil. Rio de Janeiro: Fundação Heinrich Boll, ActionAid, 2009.

SAFFIOTI, HELEIETH I. B. Gênero, patriarcado, violência. $1^{\circ} \mathrm{ed}$. São Paulo: Fundação Perseu Abramo, 2004,151p.

SCHIEBINGER, L. O feminismo mudou a ciência. Bauru: Edusc, 2001.

SCOTT, J. Gênero: uma categoria útil de análise histórica. NET, New York, Columbia University Press,1989. Disponível em: http://wesleycarvalho.com. br/wp-content/uploads/G\%C3\%AAnero-Joan-Scott.pdf. Acesso em 13 de junho de 2013.

SILVA, Elizabeth Bortolaia. Des-construindo gênero em ciência e tecnologia. Cadernos Pagu, São Paulo, v. 10, p. 07-20, 1998.

STEPAN, Nancy Leys. A Hora da Eugenia: raça, gênero e nação na América Latina Rio de Janeiro: Editora. Fiocruz, 2005. 